\title{
The Koebner phenomenon: psoriasis in tattoos
}

\section{Salvador Arias-Santiago MD PhD, María José Espiñeira-Carmona MD, José Aneiros-Fernández MD}

A $\mathrm{n}$ otherwise healthy 18 -year-old man presented with skin lesions that had appeared on 2-week-old tattoos on his forearms. The lesions were neither itchy nor painful. Physical examination showed welldemarcated, mildly erythematous papules with silver scales (Figure 1). He had no family history of skin problems and no previous skin conditions. A skin biopsy was performed and results were compatible with psoriasis (Appendix 1, available at www.cmaj.ca/lookup/suppl /doi:10.1503/cmaj.111299/-/DC1). Tattooinduced psoriasis was diagnosed and treated with calcipotriene cream for 4 weeks with satisfactory resolution.

Koebner phenomenon was initially reported as the formation of psoriasiform lesions after cutaneous trauma in the uninvolved skin of people with psoriasis. More recently, the definition has been extended to include lesions developed after trauma in people with no pre-existing dermatosis. Several other skin diseases, such as lichen planus, vitiligo and Darier disease, can present with Koebner phenomenon. ${ }^{1}$ Koebner phenomenon occurs in about $25 \%$ of people with psoriasis after various traumatic injuries, but these episodes may be unrecognized. ${ }^{2}$

Despite the common occurrence of this phenomenon, the specific mechanisms underlying it have not been elucidated; cytokines, stress proteins, adhesion molecules or autoantigens may be involved. ${ }^{3}$ Provoking factors include not only physical trauma, but also burns, friction, insect bites, surgical incision, allergic and irritant reactions, and radiation exposure. ${ }^{4}$ In this patient, repeated trauma involved in the tattoo procedure was the provoking factor for psoriasis. The period from injury to skin disease is generally between 10 and 20 days, but may range from 3 days to 2 years. ${ }^{4}$ Treatment involves treating the underlying condition. This presentation illustrates that Koebner phenomenon can occur in

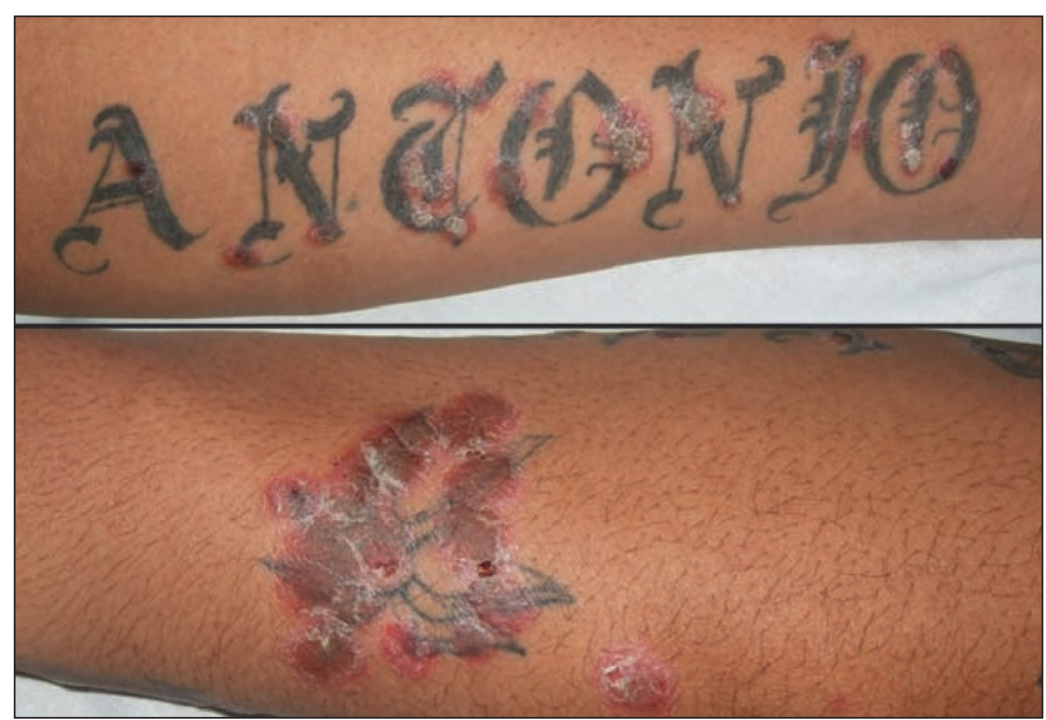

Figure 1: Well-demarcated papules with silver scales and mild erythema on the tattoos of an 18-year-old man.

patients without pre-existing dermatosis. Those with psoriasis should be aware that getting a tattoo may trigger the phenomenon.

\section{References}

1. Weiss G, Shemer A, Trau H. The Koebner phenomenon: review of the literature. J Eur Acad Dermatol Venereol 2002;16:241-8.

2. Boyd AS, Neldner KH. The isomorphic response of Koebner. Int J Dermatol 1990;29:401-10.

3. Raychaudhuri SP, Jiang WY, Raychaudhuri SK. Revisiting the Koebner phenomenon: role of NGF and its receptor system in the pathogenesis of psoriasis. Am J Pathol 2008;172:961-71.

4. Sagi L, Trau H. The Koebner phenomenon. Clin Dermatol 2011; 29:231-6.

Clinical images are chosen because they are particularly intriguing, classic or dramatic. Submissions of clear, appropriately labelled high-resolution images must be accompanied by a figure caption and the patient's written consent for publication. A brief explanation (250 words maximum) of the educational significance of the images with minimal references is required.
Competing interests: None declared.

This article has been peer reviewed.

Affiliations: From the

Departments of

Dermatology and

Pathology, San Cecilio

University Hospital; Baza

General Hospital; and the

School of Medicine,

Granada University,

Granada, Spain

Correspondence to:

Salvador Arias-Santiago, salvadorarias@hotmail.es

CMAJ 2013. DOI:10.1503 /cmaj.111299 